Smith, T.J., and H.M. Camper. 1973. Registration of 'Essex'. Crop Sci. 13:495.

Urrea-Gomez, R., H. Ceballos, S. Pandey, A.F.C. Bahia-Filho, and L.A. Leon. 1996. A greenhouse screening technique for acid soil tolerance in Maize. Agron. J. 88:806-812.

Villagarcia, M.R., T.E. Carter, Jr., T.W. Rufty, F.S. Farmer, and M.W.
Jennette. 1998. Variation in root morphology of promising drought tolerant soybean plant introductions. p. 165. In Agronomy abstracts. ASA, Madison, WI.

Wright, S.R., M.W. Jennette, H.D. Coble, and T.W. Rufty. 1999. Root morphology of young soybean, sicklepod, and Palmer amaranth. Weed Sci. 47:706-711.

\title{
Major and Minor Genes for Stimulation of Striga hermonthica Seed Germination in Sorghum, and Interaction with Different Striga Populations
}

\author{
B. I. G. Haussmann, D. E. Hess, G. O. Omanya, B. V. S. Reddy, H. G. Welz, and H. H. Geiger*
}

\begin{abstract}
The parasitic angiosperms Striga hermonthica (Del.) Benth. and S. asiatica (L.) Kuntze severely constrain cereal production in subSaharan Africa. A resistance mechanism to these root parasites in sorghum [Sorghum bicolor (L.) Moench] is low exudation of striga seed germination stimulants. The trait is controlled by a single recessive gene in the sorghum $\times S$. asiatica interaction, but information is lacking for $\boldsymbol{S}$. hermonthica. Objectives of this investigation were to study the inheritance of stimulation of $S$. hermonthica seed germination in three $F_{2}$ and two $F_{3: 5}$ recombinant inbred populations of sorghum, and to determine the effects of striga populations from Mali, Niger, and Kenya on the effectiveness of the low-stimulant character. An agar-gel assay was employed for this purpose. In this laboratory assay, the maximal distance between sorghum rootlets and germinated striga seed ("maximal germination distance") reflects the magnitude of germination stimulation. Bimodal frequency distributions supported the hypothesis of one recessive gene with a major effect for low maximal germination distance in progenies from crosses of lowstimulant lines (Framida, IS 9830) with a high-stimulant line (E 36-1), tested with striga from Mali or Niger. However, low- versus highstimulant classes were not always clearly distinct, indicating that additional minor genes modified maximal germination distance in the progenies. The Kenyan striga population led to higher maximal germination distances and larger overlap of low- and high-stimulant classes than striga from Mali or Niger. Minor genes seemed therefore more important with Kenyan striga seed. The general involvement of minor genes in stimulating $S$. hermonthica seed germination was also evident from the heritable, quantitative variation observed in $F_{3: 5}$ lines derived from a cross of the high-stimulant lines $\mathbf{N} 13$ and $E$ 36-1. Because of the higher sensitivity of Kenyan striga to germination stimulation, the low-stimulant character may be less effective in Kenyan fields.
\end{abstract}

$\mathrm{P}$ ARASItic Flowering WEeds of the genus Striga (Scrophulariaceae) cause great losses to cereal production in sub-Saharan Africa. The economically most important species are $S$. hermonthica and S. asiatica. Twothirds of the acreage used for cereal production in 17 sub-Saharan countries are estimated to be infested by the parasite (Kim et al., 1998). Most cultivars planted are highly susceptible to striga.

B.I.G. Haussmann, G.O. Omanya, and H.H. Geiger, Univ. of Hohenheim, 350 Institute of Plant Breeding, Seed Science, and Population Genetics, 70593 Stuttgart, Germany; D.E. Hess, International Crops Research Institute for the Semi-Arid Tropics (ICRISAT), B.P. 320, Bamako, Mali; B.V.S. Reddy, ICRISAT, Patancheru 502 324, Andhra Pradesh, India; and H.G. Welz, Aventis CropScience, P.O. Box 219, Seymour, IL 61875, USA. Received 13 Sept. 2000. *Corresponding author (geigerhh@uni-hohenheim.de).

Published in Crop Sci. 41:1507-1512 (2001).
Resistant sorghum cultivars could become a major component of integrated striga control packages if effective host-plant resistance were incorporated into adapted, productive cultivars. The best-described mechanism of resistance in sorghum to the weed is low production of root exudates required by the striga seed to germinate. The major germination stimulant in sorghum is sorgolactone (Hauck et al., 1992), whereas sorgoleone and strigol seem to be of minor importance (Ejeta et al., 1992). Other putative mechanisms of resistance to striga include mechanical barriers, inhibition of germ tube exoenzymes by root exudates, phytoalexine synthesis, post-attachment hypersensitive reactions, antibiosis (e.g., unfavorable phytohormone supply by the host), insensitivity to a postulated striga toxin, and avoidance through root growth habit (Ejeta et al., 1992; Ejeta and Butler, 1993; Berner et al., 1995; Heller and Wegmann, 2000). Absence of a haustorial inducer in root exudate is an improbable resistance mechanism since the haustorial inducer 2,6-dimethoxy-parabenzoquinone is thought to be produced by all plants under striga attack (Frick et al., 1996).

The agar-gel assay developed by Hess et al. (1992) is an excellent tool for screening host genotypes in the laboratory for the low-stimulant character (Vogler et al., 1996). Low stimulation of $S$. asiatica seed germination was shown to be inherited as a single recessive gene in the sorghum cultivars Framida, 555, SRN 6496 (Ramaiah et al., 1990), and SRN 39 (Vogler et al., 1996). However, in the study of Vogler et al. (1996), distinction of low- and high-stimulant groups was not very clear. The authors suggested that the $\mathrm{F}_{2}$ distributions reflected the presence of the three stimulant compounds, sorgolactone, sorgoleone, and strigol. Either the major stimulant, or the three separately or in combination, could induce germination in a 1 low: 3 high ratio in the tested $\mathrm{F}_{2}$ populations.

Quantitative variation with predominance of additive gene effects for maximal germination distance of S. hermonthica in the agar-gel assay was reported on the basis of a 9-by-9 diallel-cross study in sorghum (Haussmann et al., 2000). In the same experiment, different general combining ability effects of Framida and line 555 indicated that the low-stimulant genes (or alleles) may differ in these two lines.

While the genetics of stimulation of $S$. asiatica seed

Abbreviations: RIP, recombinant inbred population. 
Table 1. Survey of the sorghum materials and Striga hermonthica populations used in the individual agar-gel assays.

\begin{tabular}{|c|c|c|c|c|c|c|}
\hline \multirow[b]{2}{*}{ Generation } & \multirow[b]{2}{*}{ Cross } & \multirow[b]{2}{*}{$N \dagger$} & \multirow[b]{2}{*}{ Year } & \multicolumn{3}{|c|}{ Striga population } \\
\hline & & & & Mali & Niger & Kenya \\
\hline \multirow[t]{3}{*}{$\mathbf{F}_{2}$} & Framida $\times$ E 36-1 & 90 & 1996 & $\mathbf{x}+$ & & \\
\hline & $555 \times$ E 36-1 & 89 & 1996 & $\mathbf{x}$ & & \\
\hline & IS $9830 \times$ E 36-1 & 90 & 1996 & $\mathbf{x}$ & & \\
\hline \multirow[t]{3}{*}{$\mathbf{F}_{5}$} & IS 9830 × E 36-1 (RIP 1, Set 1) & $696(116 \times 6)$ & 1997 & $\mathbf{x}$ & $\mathbf{x}$ & $\mathbf{x}$ \\
\hline & IS 9830 × E 36-1 (RIP 1, Set 2) & $660(110 \times 6)$ & 1998 & $\mathbf{x}$ & $\mathbf{x}$ & $\mathbf{x}$ \\
\hline & N 13 × E 36-1 (RIP 2, Set 1) & $696(116 \times 6)$ & 1997 & $\mathbf{x}$ & $\mathbf{x}$ & \\
\hline
\end{tabular}

$\dagger$ Number of tested $F_{2}$ and $F_{5}$ seedlings, respectively. (Six $F_{5}$ plants were tested from each of the 116 or $110 F_{3: 5}$ lines.)

$\uparrow$ Each cross marks an individual experiment.

germination have been studied extensively (Ramaiah et al., 1990; Vogler et al., 1996), relatively little is known about the inheritance of stimulation of S. hermonthica seed germination and the effect of different striga populations on the expression of this character. Objectives of this investigation were to study the inheritance of stimulation of $S$. hermonthica seed germination in segregating populations of sorghum, and to determine the effects of striga populations from Mali, Niger, and Kenya on the effectiveness of the low-stimulant character.

\section{MATERIALS AND METHODS}

\section{Genetic Materials}

The genetic materials comprised three $\mathrm{F}_{2}$ and two $\mathrm{F}_{3: 5}$ recombinant inbred populations (RIPs) of sorghum (Table 1). The $\mathrm{F}_{2}$ populations were derived from crosses of the lowstimulant cultivars Framida, 555, and IS 9830 with the highstimulant line $\mathrm{E}$ 36-1. Each $\mathrm{F}_{2}$ population was represented by

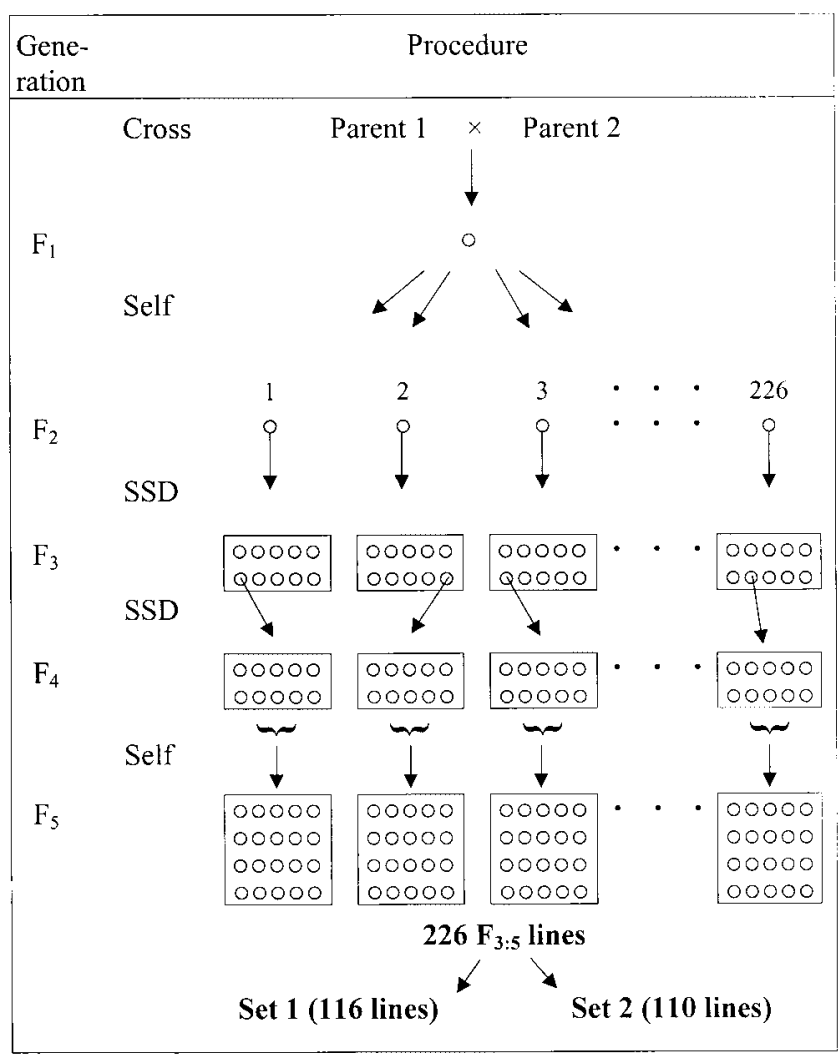

Fig. 1. Schematic representation of the development of the $F_{3: 5}$ lines forming the two recombinant inbred populations. SSD = single seed descent; circles = individual plants; rectangulars = lines.
89 or 90 individual $F_{2}$ plants. The two recombinant inbred populations were produced from crosses between IS 9830 and E 36-1 (RIP 1), and N 13 and E 36-1 (RIP 2), respectively. Line N 13 is a high-stimulant line with "mechanical" resistance (e.g., lignification of cell walls) to striga under field conditions (Ramaiah, 1987). The crosses were selfed and $226 \mathrm{~F}_{2}$ plants per population advanced by single-seed descent to the $\mathrm{F}_{4}$ generation (Fig. 1). The $\mathrm{F}_{4}$ lines were multiplied by selfing 40 panicles per line, and the resulting $\mathrm{F}_{5}$ seed was bulked. These $\mathrm{F}_{3}$-plant derived bulks in $\mathrm{F}_{5}$ are called $\mathrm{F}_{3: 5}$ lines here. Each recombinant inbred population was divided into Set 1 (116 $\mathrm{F}_{3: 5}$ lines, tested in 1997) and Set $2\left(110 \mathrm{~F}_{3: 5}\right.$ lines, tested in 1998), to allow for a verification of the first year's results. However, for RIP 2, only Set 1 was tested for stimulation of striga seed germination.

\section{Agar-Gel Assay}

An agar-gel assay (Hess et al., 1992) was employed to test the various sorghum populations for stimulation of striga seed germination. For each lot of 10 Petri dishes (9-cm diam), $500 \mathrm{mg}$ striga seed were surface-sterilized as described by Hess et al. (1992) and preconditioned for $12 \mathrm{~d}$ at $28^{\circ} \mathrm{C}$ in the dark. About 4500 conditioned striga seed $(150 \mathrm{Fl}$ of settled seed) were pipetted into each plate. Twenty to $25 \mathrm{~mL}$ autoclaved $0.7 \%$ (w/v) water agar, cooled but not yet solidified, was poured into each plate in a manner such that a uniform distribution of striga seed throughout the agar was achieved. A 24-h old sorghum seedling was inserted with its rootlet (about $1.5 \mathrm{~cm}$ long) into the solidifying agar near one edge of the plate, with the root tip pointing across the plate. Because the sorghum root occasionally fails to grow or grows above the medium, a second seedling was placed opposite to the first, and the one less favorably oriented or less vigorously growing was removed within $12 \mathrm{~h}$. After $5 \mathrm{~d}$ of incubation at $28^{\circ} \mathrm{C}$ in the dark, germination of striga seed was easily visible through the bottom of the plate with a dissecting microscope. The maximal germination distance was recorded, i.e., the distance between the host root and the most distantly germinated striga seed. Plates with abnormal growth of the sorghum seedling were treated as missing observations.

\section{Striga Populations and Experimental Design}

The three $F_{2}$ populations were tested in 1996 by means of S. hermonthica seed harvested at Samanko, Mali, in November 1994. Each population was handled as a separate experiment. The 89 or $90 \mathrm{~F}_{2}$ seedlings per population (resulting in 89 or 90 petri plates), were completely randomized. The parent lines were evaluated in five replications, along with their progenies.

Sets 1 and 2 of RIP 1 (IS $9830 \times$ E 36-1) were evaluated in 1997 and 1998, respectively, by means of S. hermonthica populations from Samanko, Mali, Bengou, Niger, and Kibos, Kenya. The respective striga seed had been harvested in 1995 and 1996. Set 1 of RIP 2 (N 13 × E 36-1) was tested in 1997 
with the same two West African striga populations as Set 1 of RIP 1. Because of limited personnel and testing facilities, each genetic material $\times$ striga population combination was analyzed in a separate 11-by-11 lattice design. The $\mathrm{F}_{3: 5}$ lines of each set were randomized together with the corresponding two parent lines and three (1997) or nine (1998) check cultivars, including the low-stimulant genotype SRN 39 and the Kenyan striga-tolerant cultivar Seredo. Six replications were employed in each experiment. Hence each original $F_{3}$ plant was represented by six random $\mathrm{F}_{5}$ offspring, each in a separate Petri dish. Each experiment was conducted over $3 \mathrm{wk}$, with two out of the six replications being performed each week.

All tests were carried out in the laboratory at ICRISATMali, except that for Set 1 of RIP 1 with the Kenyan striga seed, which was performed at the University of Hohenheim, Germany. All plates and remnant preconditioned striga seed were autoclaved before final disposal.

\section{Statistical Analysis}

The chi-square goodness-of-fit test (Gomez and Gomez, 1984) was used to check the hypothesis of a single recessive gene for low stimulant production in the $\mathrm{F}_{2}$ populations. Since $25 \%$ of the $\mathrm{F}_{3: 5}$ lines of the RIPs were expected to segregate for the maximal germination distance under the single gene hypothesis, the frequency distributions and the chi-square test were not based on the line means but on the individual $F_{5}$ plant data observed in the six replications (696 and 660 in Sets 1 and 2). Ratios of low-stimulant to high-stimulant phenotypes were expected to be 1:3 and 15:17 in the $F_{2}$ and $F_{5}$ generations, respectively. In the literature, genotypes with a maximal germination distance below $10 \mathrm{~mm}$ are usually classified as lowstimulant types (Hess et al., 1992). However, in the present study with multiple populations and no clear border between the low- and high-stimulant types, $\mathrm{F}_{2}$ or $\mathrm{F}_{5}$ plants were classified as low-stimulant when their maximal germination distance was below the mean plus twice the standard deviation of the low-stimulant parent.

Analyses of variance combined across striga populations were performed with the lattice-adjusted $\mathrm{F}_{3: 5}$-line means of each set of material from the RIPs by the statistical software PLABSTAT (Utz, 1998). The effects of the sorghum genotypes were considered as random and those of the striga populations as fixed. Since the distribution of the data was bimodal in most cases, mean squares were computed instead of variance components, and the $F$-tests applied are only approximate.

\section{RESULTS \\ $F_{2}$ Populations}

Low mean maximal germination distances confirmed the low-stimulant character of the parents Framida, 555, and IS 9830 (Fig. 2). Small standard errors of the parent lines indicated a high precision of the data. The frequency distributions of the three $\mathrm{F}_{2}$ populations were bimodal, and the $\mathrm{F}_{2}$ seedlings could be classified into a low-stimulant and a high-stimulant group. The corresponding chi-square test was in agreement with the single-gene hypothesis for low stimulant production (1:3 ratio of low-: high-stimulant seedlings) in the $\mathrm{F}_{2}$ populations derived from the crosses Framida $\times$ E 36-1 and IS $9830 \times \mathrm{E} \mathrm{36-1} \mathrm{(Table} \mathrm{2).} \mathrm{However,} \mathrm{there} \mathrm{was} \mathrm{an}$ excess of low-stimulant plants in the $\mathrm{F}_{2}$ population derived from the cross $555 \times$ E 36-1, because of the higher standard deviation of line 555 and, therefore, the higher
Number of $F_{2}$ plants

a)

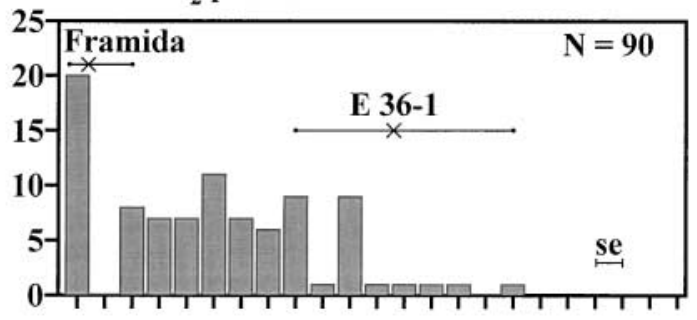

b)

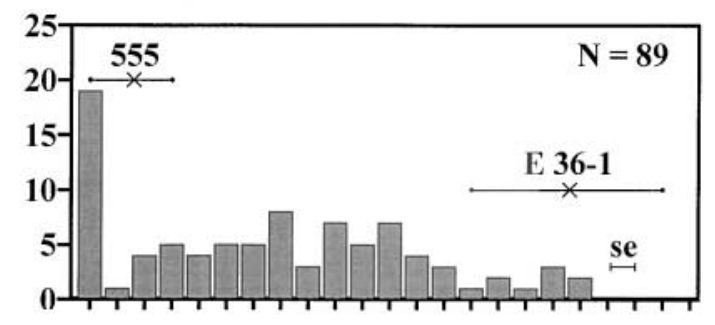

c)

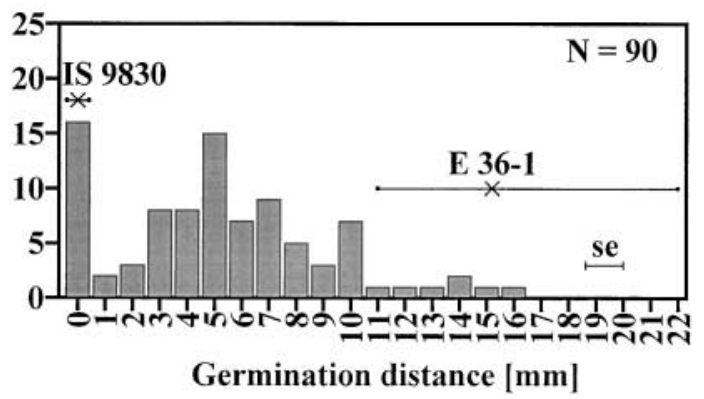

Fig. 2. Frequency distributions for maximal germination distance in the agar-gel assay of $F_{2}$ populations derived from the crosses (a) Framida $\times$ E 36-1, (b) $555 \times$ E 36-1, and (c) IS 9830 $\times$ E 36-1. $\rightarrow$ indicates the mean and range of observations among seedlings of a given parent line; se = standard error of parent means.

limit for the low-stimulant class. In all three $F_{2}$ populations, there was extensive variation within the highstimulant groups. Most seedlings in the high-stimulant groups had maximal germination distances lower that the high-stimulant parent E 36-1.

\section{RIP 1 (IS $9830 \times$ E 36-1)}

Both sets of $F_{3: 5}$ lines of RIP 1, the two parent lines, the low-stimulant standard line SRN 39 and the strigatolerant cultivar Seredo generally revealed significantly higher mean maximal germination distances with the Kenyan striga than with the two West African striga populations (Table 3 ).

The frequency distributions of the $\mathrm{F}_{5}$ plants were bimodal when tested with the two West African striga

Table 2. Chi-square test for deviations from a 1:3 low- (LS): highstimulant (HS) ratio in the three $F_{2}$ populations for maximal germination distance (GD) in the agar-gel assay.

\begin{tabular}{lccrc}
\hline Cross combination & $\begin{array}{c}\text { Range of GD in } \\
\text { the LS class } \dagger\end{array}$ & $\begin{array}{c}\text { Observed ratio } \\
\text { LS:HS }\end{array}$ & $\chi^{2}$ & $\boldsymbol{P}$ \\
\hline & $\mathrm{mm}$ & & & \\
Framida $\times$ E 36-1 & $\mathbf{0 - 2}$ & $\mathbf{2 8 : 6 2}$ & 1.48 & $\mathbf{0 . 1 0 - 0 . 2 5}$ \\
$\mathbf{5 5 5} \times \mathbf{E ~ 3 6 - 1}$ & $0-5$ & $38: 51$ & 13.93 & $<0.01$ \\
IS 9830 $\times$ E 36-1 & 0 & $16: 74$ & 2.13 & $0.10-0.25$ \\
\hline
\end{tabular}

$\dagger$ Upper class limit: mean maximal germination distance +2 standard deviations of the low-stimulant parent. 
Table 3. Means of selected cultivars and the $F_{3: 5}$ lines of Sets 1 and 2 of RIP 1 (IS $9830 \times$ E 36-1) for maximal germination distance in the agar-gel assays, using striga seed from Mali, Niger, and Kenya.

\begin{tabular}{|c|c|c|c|c|c|c|}
\hline \multirow[b]{2}{*}{ Year } & \multirow[b]{2}{*}{ Striga } & \multicolumn{5}{|c|}{ Mean maximal germination distance $(\mathrm{mm}) \dagger$} \\
\hline & & IS 9830 & E 36-1 & SRN 39 & Seredo & $\mathbf{F}_{3: 5}$ lines \\
\hline \multirow{3}{*}{$\begin{array}{l}1997 \\
\quad \text { (Set 1) }\end{array}$} & Mal & 2.7ab & 18. & 1.3 & 15. & 8.7a \\
\hline & $\mathbf{N}$ & 0.0 & 18 & 0. & 17. & $9.0 \mathrm{a}$ \\
\hline & KeI & & & & & $14.0 \mathrm{~b}$ \\
\hline \multirow{3}{*}{$\begin{array}{l}1998 \\
\quad \text { (Set 2) }\end{array}$} & Mali & $0.8 \mathrm{a}$ & 21.8ab & 1.1a & 11.5a & 8.4a \\
\hline & & & 20. & 0.0 & 13. & $8.5 \mathrm{a}$ \\
\hline & Kenya & $5.6 b$ & $24.7 \mathrm{~b}$ & $6.7 \mathrm{~b}$ & $18.7 \mathrm{~b}$ & $13.3 b$ \\
\hline
\end{tabular}

$\uparrow$ Means followed by the same letter within columns and years are not significantly different as determined by the least significant difference between striga populations at the 0.05 probability level.

populations (Fig. 3a and b, left and middle). The chisquare test led to acceptance of the single-gene hypothesis for low stimulant production (15:17 ratio of low-: high-stimulant seedlings) in Set 1 with the striga seed from Mali and in Set 2 with both West African striga sources (Table 4). As observed with the $F_{2}$ populations, there was broad variation in the high-stimulant groups. No clear bimodality (though a strong negative kurtosis) resulted from the Kenyan striga population (Fig. 3c); therefore, the chi-square test was not applied to the Kenyan data sets.

In the combined analyses of variance across striga populations, the mean squares due to striga populations,
Table 4. Chi-square test for deviations from a 15:17 low- (LS): high-stimulant (HS) ratio in Sets 1 and 2 of RIP 1 (IS $9830 \times$ $E$ 36-1) for maximal germination distance (GD) in the agargel assay with striga populations from Mali and Niger $\dagger$.

\begin{tabular}{|c|c|c|c|c|c|}
\hline $\begin{array}{l}\text { Sorghum } \\
\text { material }\end{array}$ & $\begin{array}{c}\text { Striga } \\
\text { population }\end{array}$ & $\begin{array}{l}\text { GD range in } \\
\text { the LS class }\end{array}$ & $\begin{array}{c}\text { Observed ratio } \\
\text { LS:HS }\end{array}$ & $x^{2}$ & $P$ \\
\hline & & $\mathbf{m m}$ & & & \\
\hline Set 1 & M & 0-8 & 8 & 0.01 & $0.90-0.95$ \\
\hline$I=696)$ & Nig & 0 & 268 & 19.24 & $<0.01$ \\
\hline Set 2 & Mali & $0-5$ & 300: & 0.48 & $0.25-0.50$ \\
\hline$(N=660)$ & Niger & 0-3 & 298:362 & 0.72 & $0.25-0.50$ \\
\hline
\end{tabular}

$\dagger$ The chi-square test was not applied to the data with the Kenyan striga, since the corresponding frequency distributions were not clearly bimodal. $\$$ Upper class limit: mean maximal germination distance +2 standard deviations of the low-stimulant parent.

$\mathrm{F}_{3: 5}$ lines, and interaction between $\mathrm{F}_{3: 5}$ lines and striga populations were highly significant in both sets of material (Table 5). Maximal germination distance was more highly correlated between the two West African striga populations (coefficient of correlation $r=0.92$ and 0.91 in Sets 1 and 2, respectively, significant at $P \leq 0.01$ ) than between either of the West African and the Kenyan striga population (correlation coefficient ranging from 0.74 to $0.87, P \leq 0.01$, data not shown).

\section{RIP 2 (N $13 \times$ E 36-1)}

Although both parental lines of RIP 2 were highstimulant types, there was significant genetic variation
RIP 1, Set $1(N=696)$

a)

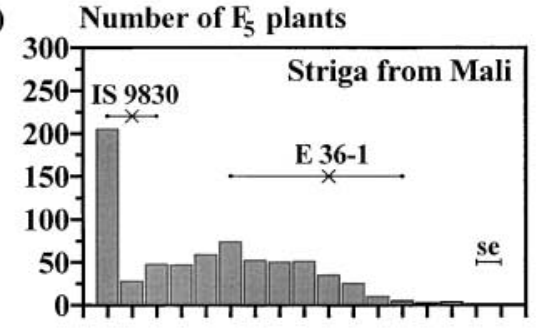

b)

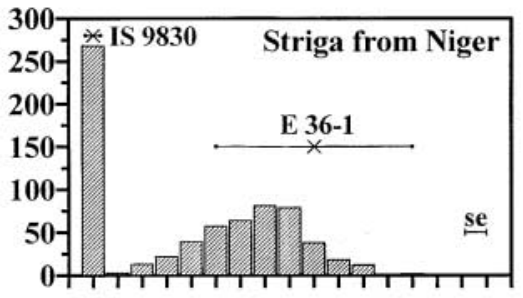

c)

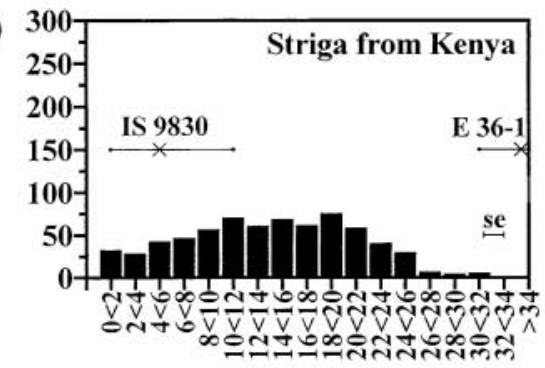

Germination distance $|\mathrm{mm}|$
RIP 1, Set $2(N=660)$
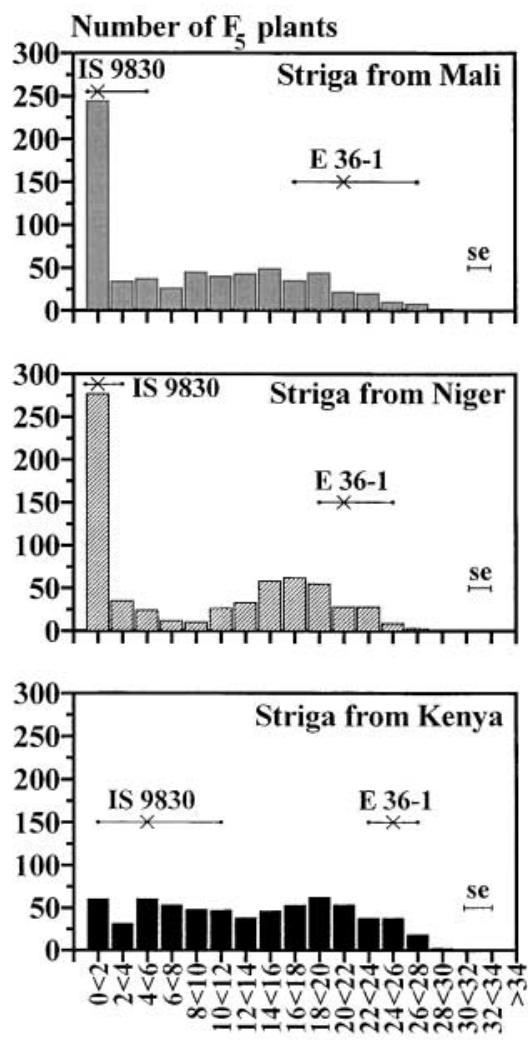

Germination distance $[\mathrm{mm}]$

RIP 2, Set $1(\mathrm{~N}=696)$
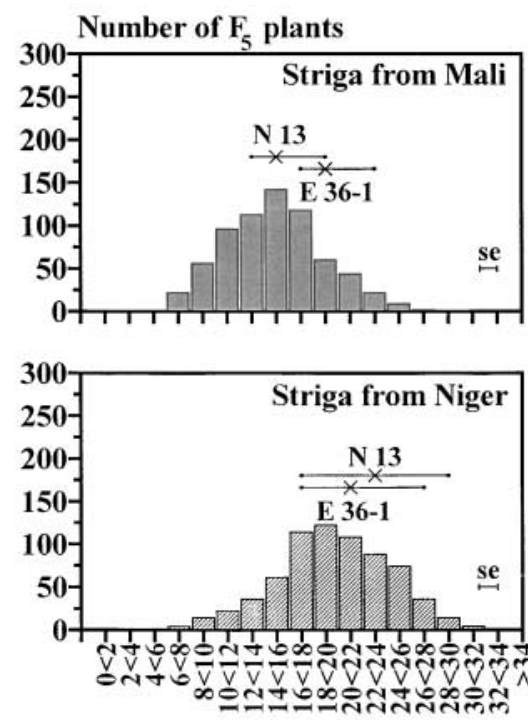

Germination distance $[\mathrm{mm}]$

Fig. 3. Frequency distributions of the individual $F_{5}$ plants in Sets 1 and 2 of recombinant inbred population (RIP) 1 (IS 9830 $\times$ E 36-1) and in Set 1 of RIP 2 (N $13 \times$ E 36-1), for maximal germination distance in the agar-gel assay with striga populations from (a) Mali, (b) Niger, and (c) Kenya. $\longrightarrow \leftarrow$ indicates the mean and range of observations among seedlings of a given parent line; se $=$ standard error of parent means. 
Table 5. Mean squares of striga populations, $F_{3: 5}$ lines, and their interaction in RIP 1 (IS 9830 $\times$ E 36-1) and RIP 2 (N $13 \times$ 36-1) for maximal germination distance in the agar-gel assay, combined across striga populations from Mali, Niger and Kenya for RIP 1, and Mali and Niger for RIP 2.

\begin{tabular}{|c|c|c|c|}
\hline \multirow[b]{2}{*}{ Source of variation } & \multicolumn{2}{|c|}{ RIP $1 \dagger$} & \multirow[b]{2}{*}{ RIP 2} \\
\hline & Set 1 & Set 2 & \\
\hline Striga population (S) & (2) $1031.7 * *$ & (2) $846.1 * *$ & (1) $1405.5 * *$ \\
\hline $\mathbf{F}_{3: 5}$ lines $(\mathbf{G})$ & (115) $99.4 * *$ & (109) $121.4 * *$ & (115) $9.1^{* *}$ \\
\hline $\mathbf{S} \times \mathbf{G}$ & (230) $7.9 * *$ & (218) 5.9** & (115) $3.3^{* *}$ \\
\hline Error & (1596) 3.1 & (1620) 3.7 & (1004) 2.1 \\
\hline
\end{tabular}

** Significant at the 0.01 probability level.

$\dagger$ Degrees of freedom for RIP 1, Sets 1 and 2, and RIP 2, respectively, are numbers in parentheses preceding mean squares.

among the $\mathrm{F}_{3: 5}$ lines for the maximal germination distance (Table 5). The mean squares due to striga populations and interaction effects between $\mathrm{F}_{3: 5}$ lines and striga populations were also highly significant. The frequency distributions were unimodal and normal for the $\mathrm{F}_{5}$ seedlings tested with the striga population from Mali (Fig. $3 a$, right). With the striga population from Niger, the frequency distribution had a slight negative skewness (Fig. 3b, right). Transgressive segregation towards lower maximal germination distances was observed with both striga populations.

\section{DISCUSSION}

The observed bimodal frequency distributions for maximal in vitro germination distance of $F_{2}$ and $F_{5}$ plants from crosses of low- $X$ high-stimulant parent lines tested with West African striga demonstrate the presence of one recessive gene for low stimulation of $S$. hermonthica seed germination. However, in none of the experiments were low- and high-stimulant plants clearly distinct. Because of this fact, it proved difficult to differentiate between the two groups for an unbiased application of the chi-square test. In the present study, the upper limit for the low-stimulant group was defined as the mean plus twice the standard deviation of the low-stimulant parent. About $95.4 \%$ of a random sample of homozygous low-stimulant genotypes would be expected to lie within that range (Athen and Bruhn, 1980). The fact that the single-gene hypothesis could not be accepted in all instances, and the large variation observed in the high-stimulant groups suggest that minor genes modify maximal germination distance, possibly by influencing the quantity and/or composition of striga germination stimulants. The involvement of minor genes in stimulation of striga seed germination was also evident from the heritable, quantitative variation observed in progenies derived from a cross between the two high-stimulant lines N 13 and E 36-1. The reported presence of at least three germination stimulants in sorghum root exudates (Ejeta et al., 1992; Siame et al., 1993; Vogler et al., 1996) provides a physiological explanation of multiple genes controlling the stimulation of S. hermonthica seed germination.

The Kenyan striga population caused larger maximal germination distances in the parent lines, checks, and the $\mathrm{F}_{3: 5}$ lines of RIP 1 than the striga populations from Mali and Niger. The observations from the first year were confirmed in the second year with independent striga seed samples. However, these results need further confirmation with a larger set of sorghum genotypes. It also remains unclear whether Kenyan striga reacts stronger to sorgolactone, the major germination stimulant exuded by sorghum roots, or to sorgoleone and strigol, stimulants thought to be of minor importance (Ejeta et al., 1992). The overlap of low- and high-stimulant groups was so strong, that the frequency distributions of the $F_{3: 5}$ lines of RIP 1 challenged with Kenyan striga could not be considered as bimodal or qualitative. This points to the increasing importance of minor genes.

The correlations among the striga populations for maximal germination distance in RIP 1 suggest greatest similarity between the two West-African striga populations. Similarly, Koyama (2000a), using isozyme and random amplified polymorphic DNA (RAPD) marker techniques, found striga samples from West African sites to be more closely related to each other than to an East African population.

Because of the apparently higher sensitivity of the Kenyan striga seed to germination stimulants, the lowstimulant character might be a less effective resistance mechanism in Kenyan than in West African fields. In fact, Omanya (2000) found correlations between maximal germination distance and resistance of RIP 1 under field conditions to be stronger in Mali than in Kenya. On the other hand, in diallel crosses of sorghum, Haussmann et al. (2001) observed stronger correlations between maximal germination distance and resistance under field conditions in Kenya than in Mali. According to Vasudeva Rao (1984), correlations between weak stimulation of striga seed germination and resistance in the field are mostly positive, but depend on the materials under investigation and the test environments. Wegmann (personal communication, 1997) suggests that specific conditions like ethylene production by microorganisms caused by abiotic stress could render the low-stimulant character less effective in certain site $\times$ season combinations.

Significant genotype $\times$ environment interactions for striga resistance in sorghum have been reported by several authors (e.g., Ramaiah, 1987; Haussmann et al., 2001; Omanya et al., 2000). In field trials across diverse geographic regions, the total genotype $\times$ environment interaction variance comprises interaction effects between genotypes and locations (soil, temperature, precipitation, etc.), between genotypes and putative striga races or biotypes, and the corresponding three-way interaction. The three types of interaction, however, could only be separated by evaluating the sorghum materials at each location against striga populations of different geographic origin. For reasons of quarantine, this cannot be done in Africa. In the present agar-gel assays with the two RIPs, the importance of $\mathrm{F}_{3: 5}$ line $\times$ striga population interaction was relatively small, as indicated by the rather high correlations among the various striga populations. However, these results concern just one resistance mechanism to striga, i.e., stimulation of striga seed germination. Other host-parasite interaction mechanisms such as penetration of striga into the host roots and subsequent growth of the parasite need to be stud- 
ied as well. Striga was reported to be a genetically highly variable parasite, and to have an extraordinary capacity to adapt to new hosts (Ejeta et al., 1992; Koyama, 2000b). Resistance to striga is partially species-specific, i.e., resistance to $S$. asiatica does not necessarily hold against $S$. hermonthica and vice versa (Ramaiah, 1984). Striga hermonthica populations with specific adaptation to sorghum and millet [Pennisetum glaucum (L.) R. Br.] have been reported, whereas other striga sources attack both host species (Vasudeva Rao and Musselman, 1987; Hess, 1994; Freitag et al., 1996). Koyama (2000b) found evidence for low selection pressure on S. hermonthica populations parasitizing susceptible sorghum varieties, and increasing selection pressure-reducing the genetic variability of the striga population-on tolerant and resistant varieties.

There is a lack of information about the population genetics of striga virulence. A better understanding of the variation for virulence among and within striga populations would facilitate the effective deployment of resistance genes against these parasites (Lane et al., 1997). There is need to resolve the origin and relatedness of parasitic races, and to elucidate the observed race $\times$ variety interactions. However, the high degree of self-incompatibility of $S$. hermonthica would render this endeavor very difficult.

Variability among Striga spp. as well as intraspecific variation must be taken into account when breeding for striga resistance (Ramaiah, 1987; Ejeta et al., 1992). In order to obtain stable resistance, breeding materials should be evaluated against multiple striga populations differing in host-specificity and across environmentally diverse testing sites.

\section{ACKNOWLEDGMENTS}

We thank I. Sangaré, S. Dembélé, A. Diallo, G. Mounkoro, N. Keita, and T. Berndl for their capable assistance in the laboratory work. The generous financial support of the German Federal Ministry for Economic Cooperation and Development (BMZ) is gratefully acknowledged (Grant No. 94.7860.3-01.100).

\section{REFERENCES}

Athen, H., and J. Bruhn. 1980. Rechnen und Mathematik. Bertelsmann Lexikon Verlag, Gütersloh, Germany.

Berner, D.K., J.G. Kling, and B.B. Singh. 1995. Striga research and control, a perspective from Africa. Plant Dis. 79:652-660.

Ejeta, G., and L.G. Butler. 1993. Host Plant Resistance to Striga. p. 561-569. In R.F Barnes et al. (ed.) International crop science I. CSSA, Madison, WI.

Ejeta, G., L.G. Butler, and A.G. Babiker. 1992. New approaches to the control of Striga. Striga Research at Purdue University. Res. Bull. RB-991. Agric. Exp. Stn. Purdue Univ., West Lafayette, IN.

Freitag, J., D.E. Hess, H.G. Welz, and H.H. Geiger. 1996. Pearl millet and sorghum specific races of Striga hermonthica in Niger. p. 472478. In M.T. Moreno et al. (ed.) Advances in parasitic plant research, Proc. of the 6th Int. Parasitic Weed Symposium, Cordoba, Spain. 16-18 April 1996. Congresos y Jornadas 36/96. Junta de Andalucia. Consejería de Agricultura y Pesca. Seville, Spain.

Frick, E., D. Frahne, and K. Wegmann. 1996. Biochemical synthesis of 2,6-Dimethoxy-parabenzo-quinone - a haustorial stimulant of Striga asiatica R (L.) Kuntze. Nat. Prod. Lettl. 9:53-59.
Gomez, K.A., and A.A. Gomez. 1984. Statistical procedures for agricultural research. 2nd ed. A Wiley-Interscience Publication. John Wiley \& Sons, Inc., Singapore.

Hauck, C., S. Muller, and H. Schildknecht. 1992. A germination stimulant for parasitic flowering plants from Sorghum bicolor, a genuine host plant. J. Plant Physiol. 139:474-478.

Haussmann, B.I.G., D.E. Hess, B.V.S. Reddy, H.G. Welz, and H.H. Geiger. 2000. Analysis of resistance to Striga hermonthica in diallel crosses of sorghum. Euphytica 116:33-40.

Haussmann, B.I.G., D.E. Hess, B.V.S. Reddy, S.Z. Mukuru, M. Kayentao, H.G. Welz, and H.H. Geiger. 2001. Quantitative-genetic parameters of sorghum growth under striga infestation in Mali and Kenya. Plant Breed. 120:49-56.

Heller, R., and K. Wegmann. 2000. Mechanisms of resistance to Striga hermonthica (Del.) Benth. in Sorghum bicolor (L.) Moench. p. 19-28 In B.I.G. Haussmann et al. (ed.) Breeding for Striga Resistance in Cereals, Proc., Workshop held at IITA, Ibadan, Nigeria. 18-20. August 1999. Margraf Verlag, Weikersheim, Germany.

Hess, D.E. 1994. Crop specific strains of Striga hermonthica in Niger. Phytopathology 84:1151

Hess, D.E., G. Ejeta, and L.G. Butler. 1992. Selecting genotypes expressing a quantitative biosynthetic trait that confers resistance to Striga. Phytochemistry 31:493-497.

Kim, S.K., J.M. Fajemisin, C. Thé, A. Adepoju, J. Kling, B. BaduApraku, M. Versteeg, R. Carsky, and S.T.O. Lagoke. 1998. Development of synthetic maize populations for resistance to Striga hermonthica. Plant Breed. 118:203-209.

Koyama, M.L. 2000a. Molecular markers for the study of pathogen variability: implications for breeding resistance to Striga hermonthica. p. 227-245. In B.I.G. Haussmann et al. (ed.) Breeding for striga resistance in cereals. Margraf Verlag, Weikersheim, Germany.

Koyama, M.L. 2000b. Genetic variability of Striga hermonthica and effect of resistant cultivars on striga population dynamics. p. 247260. In B.I.G. Haussmann et al. (ed.) Breeding for striga resistance in cereals. Margraf Verlag, Weikersheim, Germany.

Lane, J.A., D.V. Child, G.C. Reiss, V. Entcheva, and J.A. Bailey. 1997. Crop resistance to parasitic plants. p. 81-97. In I.R. Crute et al. (ed.) The Gene-for-Gene Relationship in Plant Parasite Interactions. CAB International, Oxon, UK.

Omanya, G.O., B.I.G. Haussmann, D.E. Hess, B.V.S. Reddy, S.Z. Mukuru, H.G. Welz, and H.H. Geiger. 2000. Evaluation of laboratory, pot, and field measures of striga resistance in sorghum. p. 59-72 In B.I.G. Haussmann et al. (ed.) Breeding for striga resistance in cereals. Margraf Verlag, Weikersheim, Germany.

Ramaiah, K.V. 1984. Patterns of Striga resistance in sorghum and millets with special emphasis on Africa. p. 71-92. In Proc. of the Int. Workshop on the Biology and Control of Striga, held at Dakar, Senegal. 14-17 Nov. 1983. ICSU Press, Paris, France.

Ramaiah, K.V. 1987. Breeding cereal grains for resistance to witchweed. p. 227-242. In L.J. Musselman (ed.) Parasitic Weeds in Agriculture, Volume I, Striga. CRC Press, Boca Raton, FL.

Ramaiah, K.V., V.L. Chidley, and L.R. House. 1990. Inheritance of Striga seed-germination stimulant in sorghum. Euphytica 45:33-38.

Siame, B.A., Y. Weerasuriya, K. Wood, G. Ejeta, and L.G. Butler. 1993. Isolation of strigol, a germination stimulant for Striga asiatica R, from host plants. J. Agric. Food Chem. 41:1486-1491.

Utz, H.F. 1998. PLABSTAT, a computer program for the statistical analysis of plant breeding experiments, Version 2N (see http:// www.uni-hohenheim.de/ ipspwww/soft.html; verified April 11, 2001). Institute of Plant Breeding, Seed Science, and Population Genetics, University of Hohenheim, Stuttgart, Germany.

Vasudeva Rao, M.J. 1984. Patterns of resistance to Striga asiatica in sorghum and millets, with special reference to Asia. p. 93-111. In Proc. Int. Workshop on the Biology and Control of Striga held at Dakar, Senegal. 14-17 Nov. 1983. ICSU Press, Paris, France.

Vasudeva Rao, M.J., and L.J. Musselman. 1987. Host specificity in Striga spp. and physiological strains. p. 13-25. In L.J. Musselman (ed.) Parasitic weeds in agriculture, Volume I Striga. CRC Press, Boca Raton, FL.

Vogler, R.K., G. Ejeta, and L.G. Butler. 1996. Inheritance of low production of Striga germination stimulant in sorghum. Crop Sci. 36:1185-1191. 